\title{
ASO Author Reflections: Which Patients with Colon Cancer Refuse Recommended Surgery?
}

\author{
Gabriel S. Makar, MD $₫$, and William Davis, MD \\ Cooper Medical School of Rowan University, Camden, NJ
}

\section{PAST}

Colon cancer is responsible for the third-most cancerrelated deaths in the United States. This is despite advancements in operative techniques and perioperative care, which have greatly expanded the indications for, safety of, and benefits from cancer-directed surgery in colon cancer. Concomitantly, the internet age has granted patients greater access to both information and misinformation, pushing medicine at-large further into collaborative or patient-directed decision-making. It is paramount to understand the factors influencing patients' approach to clinical decision-making and subsequent outcomes. We sought to describe risk factors for refusal of recommended cancer-directed surgery, as well as the survival outcomes of those refusing recommended surgery.

\section{PRESENT}

In a database study of more than 288,000 patients with primary colon cancer, $1.3 \%$ of patients refused colon cancer surgery, double the refusal rate observed in breast cancer $(0.64 \%)$, where surgery also is typically undertaken with curative intent. ${ }^{1}$ Perhaps this may be attributed to the well-publicized, positive, extirpative, and reconstructive

This study was conducted at Cooper University Hospital, Department of Surgery at One Cooper Plaza Suite 410, Camden, NJ, 08103, USA.

\section{(C) Society of Surgical Oncology 2020}

First Received: 14 June 2020;

Published Online: 1 July 2020

G. S. Makar, MD

e-mail: makarg3@rowan.edu surgical outcomes experienced by patients with breast cancer even when diagnosed with later-stage disease, which colon cancer does not enjoy.

We found increased age, black race, insurance via Medicaid, and marital status other than "married" increased the odds of refusing surgery. ${ }^{2}$ Minorities had increased survival compared with Caucasians after refusing surgery, suggesting that minorities were more likely to decline surgery with earlier disease-stage than their Caucasian counterparts.

\section{FUTURE}

The decision to undergo any surgery is personal and complex; "the only minor surgery is surgery that happens to someone else." Previously, elderly patients largely attributed their refusal of surgery to a fear of complications, a common discussion when addressing surgery in any age group. ${ }^{3}$ A prospective study following patients with newly diagnosed primary colon cancer would provide much-needed insight into the decision-making process of patients refusing recommended surgery.

DISCLOSURE The authors declare that there is no conflict of interest regarding the publication of this paper.

\section{REFERENCES}

1. Gaitanidis A, Alevizakos M, Tsalikidis C, Tsaroucha A, Simopoulos C, Pitiakoudis M. Refusal of cancer-directed surgery by breast cancer patients: risk factors and survival outcomes. Clin Breast Cancer. 2018;18(4):e469-76.

2. Makar GS, Makar M, Obinero C, et al. Refusal of cancer-directed surgery in patients with colon cancer: risk factors of refusal and survival data. Ann Surg Oncol. 2020. https://doi.org/10.1245/s10 434-020-08783-1.

3. Rothman MD, Van Ness PH, O'Leary JR, Fried TR. Refusal of medical and surgical interventions by older persons with advanced chronic disease. J Gen Intern Med. 2007;22(7):982-7.

Publisher's Note Springer Nature remains neutral with regard to jurisdictional claims in published maps and institutional affiliations. 